\title{
ANALISIS KINERJA DOSEN AKUNTANSI DALAM MENGAJAR TERHADAP MAHASISWA POLITEKNIK NEGERI TANAH LAUT MENGGUNAKAN METODE TREND
}

\author{
Muhammad Shapiq Gautama ${ }^{1)}$, Insan Kamil ${ }^{2)}$, Neng Ayu Rahmawati ${ }^{3)}$ \\ 12) 3) Program Studi Akuntansi, Politeknik Negeri Tanah Laut \\ Jalan A. Yani km 06 Desa Panggung Kec. Pelaihari, Kab. Tanah Laut \\ 1) shapiq@politala.ac.id \\ 2)d1317008.akt@politala.ac.id \\ 3) d1317014.akt@politala.ac.id
}

Diterima: 14 Maret 2020. Disetujui: 23 Juni 2020. Dipublikasikan: Juni 2020

\begin{abstract}
Abstrak
Kegiatan evaluasi kinerja dosen merupakan rutinitas suatu perguruan tinggi dalam meningkatkan kualitas internal secara berkelanjutan. Untuk mengetahui kerangka pencapaian suatu misi dalam organisasi yang baik, haruslah selalu diadakan evaluasi secara terus menerus. Evaluasi tersebut haruslah dilakukan dengan cara mengukur kinerjanya sehingga aktivitas atau kegiatan dosen dapat dimonitor secara berkala atau periodic. Kinerja dosen harus dinilai agar kita mengetahui kualitas dari dosen tersebut. Agar mahasiswa dapat menimba ilmu pada dosen tersebut lebih banyak dan tertata. Penelitian ini menggunakan metode analisis Trend yang mana terdapat 13 dosen program studi akuntansi Politeknik Negeri Tanah Laut. Metode analisis Trend merupakan suatu metode yang dapat mengetahui kenaikan dan penurunan objek yang akan diteliti ataupun dapat meramalkan kondisi data dimasa yang akan datang. Hasil penelitian dari analisis terdapat beberapa dosen yang mengalami kenaikan ataupun penurunan dalam proses mengajar, dari segi kenaikan tersebut dikarenakan dosen tersebut mampu mencairkan suasana dan mudah dalam penyampaian materi dan dari segi penurunan yaitu dosen tersebut kurang bisa dalam mencairkan suasana sehingga terkadang mahasiswa tersebut bisa mengantuk. Oleh sebab itu, dosen harus bisa mencairkan suasana sehingga mahasiswa dapat menerima apa yang dijelaskan.

Kata kunci: Kinerja, Dosen, Kuesioner, Metode Trend, Kenaikan dan Penurunan
\end{abstract}

Abstract

Lecturer performance must be assessed so that we know the quality of the lecturer. Thus, students can gain more knowledge from the lecturer and be organized. This study uses the Trend analysis method where there are 13 lecturers in Accounting Study Program, the State Polytechnic of Tanah Laut. The trend analysis method is a method that can figure out the increase and decrease of objects to be studied or can predict the condition of the data in the future. The results of the analysis showed that there were several lecturers who experienced an increase or decrease in the teaching process, in terms of the increase because the lecturer was able to dilute the atmosphere and was easy in delivering the material and in terms of the decline, the lecturer was less able to dilute the atmosphere so that sometimes the student could get sleepy. Therefore, lecturers must be able to break the ice so that students can accept what is explained.

Keywords: Performance, Lecturer, Questionnaire, Trend Method, Increase and Decrease

\section{PENDAHULUAN}

Perguruan tinggi adalah tempat dimana seseorang dapat melanjutkan pendidikan kejenjang yang lebih tinggi. Jenis perguruan tinggi diantaranya yaitu, universitas, akademi, institut, sekolah tinggi dan politeknik. Menurut KEMENRISTEK DIKTI pada tahun 2018, jumlah Perguruan Tinggi Negeri (PTN) di Indonesia sebanyak 122 dan Perguruan Tinggi Swasta (PTS) sebanyak 3.128 yang tersebar di seluruh Indonesia termasuk di Kalimantan Selatan. Kalimantan Selatan 
juga memiliki beberapa perguruan tinggi yang tidak kalah bagus dengan perguruan tinggi lainnya. Banyak perguruan tinggi yang menjadi primadona bagi calon mahasiswa yang ingin menyambung pendidikannya. Contohnya seperti Universitas Lambung Mangkurat, Universitas Islam Negeri Antasari, Politeknik Negeri Banjarmasin, dan Politeknik Negeri Tanah laut serta masih banyak lagi perguruan tinggi swasta yang ada di Kalimantan Selatan.

Politeknik Negeri Tanah laut yang terletak di Jl. Ahmad Yani km.6, Desa Panggung, Kecamatan Pelaihari, Kabupaten Tanah Laut. Politeknik ini memiliki slogan \#masadepanPASTI yang telah memberi warna pendidikan di Kalimantan Selatan khususnya wilayah Kabupaten Tanah laut. Politeknik Negeri Tanah Laut memiliki 4 program studi yaitu Program Studi Agroindustri, Program Studi Teknologi Informasi, Program Studi Teknologi Otomotif, dan Program Studi Akuntansi.

Program Studi Akuntansi di Politeknik Negeri Tanah Laut adalah program studi baru yang dibuka pada tahun 2017 hingga sekarang dengan jumlah mahasiswa sebanyak 186 orang serta dosen sebanyak 13 orang yang ahli dibidangnya masing-masing dan memberikan hasil yang maksimal dalam proses pembelajaran. Keberhasilan dosen dalam proses mengajar yaitu terletak pada kemampuan dan keahlian dosen tersebut untuk meningkatkan pendidikan, namun juga harus bisa memberikan kepuasan dalam memberikan informasi kepada mahasiswa.

Keberhasilan seorang dosen juga dapat dilihat dari kinerja dalam proses pembelajaran, maka dari itu penulis ingin mengetahui kinerja dosen terhadap mahasiswa dalam proses pembelajaran di program studi akuntansi. Oleh karena itu, penulis melakukan analisis kinerja dosen dengan menggunakan metode analisis trend. Dalam melakukan analisis ini penulis membagikan kuesioner ke 60 mahasiswa program studi akuntansi tentang kuesioner kinerja dosen. 60 mahasiswa tersebut diantaranya terdiri dari 20 mahasiswa semester II, 20 mahasiswa semester IV, dan 20 mahasiswa semester VI untuk memberikan penilaian kepada masing-masing dosen program studi akuntansi.

\section{TINJAUAN PUSTAKA}

Menurut (Razak, Syah, \& Hsb, 2016) dosen sebagai seorang tenaga pendidik memiliki prefesionalisme yang tinggi dalam pelaksanaan tugas dan tanggung jawabnya sebagai seorang tenaga pendidik, tugas dan fungsi utama seorang tenaga pendidik adalah mengelola dan melaksanakan proses pembelajaran di lembaga pendidikan, pencapaian mutu proses pembelajaran dan prestasi belajar mahasiswa di perguruan tinggi menjadi bukti kualitas dan kinerja seorang tenaga pendidik, menunjukkan adanya kompetensi diri, motivasi, kualitas maupun profesionalisme seorang dosen dalam menjalankan tugas sebagai seorang tenaga pendidik. Sedangkan menurut (Hartama \& Hartono, 2016) Dosen merupakan sumber daya yang penting di dalam mendukung proses belajar mengajar. Kualitas dosen perlu mendapat perhatian karena menentukan kualitas proses belajar mengajar.

Kegiatan evaluasi kinerja dosen merupakan rutinitas suatu perguruan tinggi dalam meningkatkan kualitas internal secara berkelanjutan. Untuk mengetahui kerangka pencapaian suatu misi dalam organisasi yang baik, haruslah selalu diadakan evaluasi secara terus menerus. Evaluasi tersebut haruslah dilakukan dengan cara mengukur kinerjanya sehingga aktivitas atau kegiatan dosen dapat dimonitor secara berkala atau periodik (Fauzi, 2016). Pengukuran kinerja merupakan salah satu faktor yang penting dalam menjamin keberhasilan suatu organisasi. Universitas Respati Yogyakarta secara rutin melakukan evaluasi kinerja dosen, namun belum menggambarkan pelaksanaan kegiatan tri dharma perguruan tinggi oleh seorang dosen karena belum mencakup bidang penelitian dan pengabdian pada masyarakat (Hamzah, Mudjihartono, \& Sutoyo, 2010). Tujuan evaluasi dosen adalah untuk : (1) meningkatkan kualitas pengajaran, (2) mengembangkan diri dosen, (3) meningkatkan kepuasan mahasiswa (4) kepuasan kerja dosen, (5) mencapai tujuan program studi/fakultas/universitas, serta (6) meningkatkan penilaian masyarakat terhadap fakultas/universitas (Sestri, 2013). Menurut (Priatna) Kinerja dosen dalam bidang pendidikan dan pengajaran mencakup pengembangan bahan ajar, pembimbingan mahasiswa, metodologi mengajar, interaksi/komunikasi dengan mahasiswa, dan melakukan kegiatan perkuliahan. 
Menurut (Pangihutan \& Simamora, 2019) rasio adalah gambaran situasi perusahaan pada suatu waktu tertentu dan dari gambaran ini sebenarnya dapat kita bayangkan kecenderungan (tren) situasi perusahaan di masa yang akan datang melalui gerakan yang terjadi pada masa lalu sampai masa kini. Analisis ini harus menggunakan teknik perbandingan laporan keuangan beberapa tahun dan dari sini digambarkan trennya. Tren analisis ini biasanya dibuat melalui grafik. Trend merupakan kecenderungan meningkat atau menurun untuk jangka waktu yang panjang (Permatasari, 2019).

Kinerja dosen harus dinilai agar kita mengetahui kualitas dari dosen tersebut. Agar mahasiswa dapat menimba ilmu pada dosen tersebut lebih banyak dan tertata. Trend adalah metode yang digunakan untuk mengetahui dari sebuah rasio yang meningkat atau menurun. Trend juga bisa digunakan sebagai forcasting untuk masa yang akan datang.

\section{METODE PENELITIAN}

Metode analisis trend adalah suatu metode yang digunakan untuk mengetahui tendensi naik, tetap atau menurun. Analisa ini disebut juga dengan Analisa Naik Turun, karena dengan analisa tersebut dapat diketahuai kenaikan atau penurunan dari masing-masing data. Trend dapat digunakan untuk meramalkan kondisi data di masa mendatang, maupun dapat digunakan untuk memprediksi data pada suatu waktu dalam kurun waktu tertentu. Objek dari penelitian ini yakni mengenai kinerja dosen terhadap mahasiswa dalam proses mengajar.

Penggunaan metode analisis trend dalam penelitian ini membuat kuesioner tentang 15 poin penilaian kinerja setiap dosen. Dosen yang akan dinilai sebanyak 13 orang dosen program studi akuntansi dan kuesioner dibagikan kepada 60 mahasiswa program studi akuntansi yang terdiri dari 20 mahsiswa semester II, 20 mahasiswa semester IV, dan 20 mahasiswa semester VI. Penelitian yang menggunakan metode analisis trend, dapat dirumuskan sebagai berikut :

Mencari nilai a dan b

$$
\mathrm{Y}=\mathrm{a}+\mathrm{bX}
$$

$$
\begin{aligned}
& \mathrm{a}=\frac{\Sigma \mathrm{Y}}{\mathrm{N}} \\
& \mathrm{b}=\frac{\Sigma \mathrm{XY}}{\Sigma \mathrm{X}^{2}}
\end{aligned}
$$

Keterangan :

$$
\begin{array}{ll}
\mathrm{Y} & =\text { Variabel yang dicari trend } \\
\mathrm{X} & =\text { Variable waktu (tahun) } \\
\mathrm{a} & =\text { Nilai konstanta } \\
\mathrm{b} & =\text { Nilai parameter }
\end{array}
$$

\section{PEMBAHASAN}

Penelitian dilakukan dengan cara menyebarkan kuesioner secara langsung kepada 60 koresponden yang terdiri dari 20 orang mahasiswa akuntansi semester II, IV dan VI. Semua kuesioner yang dibagikan telah di isi oleh 60 koresponden tanpa terkecuali. Dosen adalah tenaga pengajar yang mampu memberikan ilmu dan wawasan yang luas kepada mahasiswa sesuai dengan keahliahan dosen tersebut. Dengan begitu maka mahasiswa dapat memahami pelajaran yang diberikan oleh dosen. Namun jika dosen tersebut tidak memahami apa yang disampaikan, mahasiswa akan kebingungan dan tidak mengerti tentang pelajaran yang di ajarkan.

Tabel Error! No text of specified style in document..1 Hasil Analisis Penulis

\begin{tabular}{|c|l|l|l|l|l|l|l|l|l|l|l|l|l|c|}
\hline No & Kriteria Penilaian & D1 & D2 & D3 & D4 & D5 & D6 & D7 & D8 & D9 & D10 & D11 & D12 & D13 \\
\hline $\mathbf{1}$ & Dosen masuk tepat waktu & 196 & 163 & 91 & 97 & 177 & 198 & 187 & 113 & 114 & 124 & 162 & 129 & 111 \\
\hline $\mathbf{2}$ & $\begin{array}{l}\text { Materi kuliah sesuai } \\
\text { dengan silabus }\end{array}$ & 192 & 186 & 106 & 113 & 180 & 197 & 179 & 118 & 113 & 125 & 168 & 130 & 100 \\
\hline $\mathbf{3}$ & $\begin{array}{l}\text { Materi kuliah mudah } \\
\text { dipahami }\end{array}$ & 188 & 170 & 97 & 93 & 159 & 207 & 167 & 123 & 112 & 124 & 176 & 99 & 91 \\
\hline $\mathbf{4}$ & $\begin{array}{l}\text { Sumber pustaka mudah } \\
\text { didapat }\end{array}$ & 173 & 169 & 113 & 107 & 179 & 200 & 174 & 115 & 113 & 124 & 174 & 113 & 91 \\
\hline
\end{tabular}




\begin{tabular}{|c|c|c|c|c|c|c|c|c|c|c|c|c|c|c|}
\hline No & Kriteria Penilaian & D1 & D2 & D3 & D4 & D5 & D6 & D7 & D8 & D9 & D10 & D11 & D12 & D13 \\
\hline 5 & $\begin{array}{l}\text { Dosen memberikan } \\
\text { silabus mata kuliah }\end{array}$ & 181 & 187 & 111 & 106 & 178 & 179 & 168 & 114 & 111 & 119 & 161 & 114 & 91 \\
\hline 6 & $\begin{array}{l}\text { Dosen dapat menciptakan } \\
\text { suasana kondusif selama } \\
\text { perkuliahan }\end{array}$ & 193 & 168 & 100 & 97 & 174 & 209 & 195 & 124 & 116 & 126 & 186 & 113 & 89 \\
\hline 7 & $\begin{array}{l}\text { Perkuliahan sesuai } \\
\text { dengan jadwal yang telah } \\
\text { ditentukan }\end{array}$ & 193 & 173 & 109 & 105 & 172 & 200 & 191 & 125 & 117 & 123 & 173 & 119 & 107 \\
\hline 8 & $\begin{array}{l}\text { Dosen sudah } \\
\text { mempersiapkan materi } \\
\text { untuk mengajar }\end{array}$ & 198 & 186 & 103 & 114 & 176 & 203 & 194 & 127 & 117 & 128 & 178 & 133 & 104 \\
\hline 9 & $\begin{array}{l}\text { Penyampaian dosen } \\
\text { mudah dipahami }\end{array}$ & 188 & 162 & 98 & 89 & 162 & 212 & 171 & 126 & 112 & 124 & 179 & 97 & 88 \\
\hline 10 & $\begin{array}{l}\text { Dosen memberikan } \\
\text { informasi tentang } \\
\text { perkembangan IPEK } \\
\text { terkait mata kuliah yang } \\
\text { diajarkan }\end{array}$ & 166 & 162 & 109 & 108 & 181 & 197 & 201 & 121 & 118 & 124 & 171 & 107 & 83 \\
\hline 11 & $\begin{array}{l}\text { Dosen menggunakan } \\
\text { media pembelajaran } \\
\text { dalam menyampaikan } \\
\text { materi (LCD, papan tuis, } \\
\text { dsb) }\end{array}$ & 191 & 190 & 121 & 119 & 195 & 210 & 204 & 134 & 122 & 130 & 179 & 133 & 105 \\
\hline 12 & $\begin{array}{l}\text { Dosen memberikan } \\
\text { kesempatan bertanya }\end{array}$ & 212 & 198 & 111 & 109 & 195 & 205 & 192 & 131 & 118 & 130 & 185 & 126 & 99 \\
\hline 13 & $\begin{array}{l}\text { Jawaban dosen sudah } \\
\text { memuaskan bagi } \\
\text { mahasiswa }\end{array}$ & 194 & 172 & 94 & 85 & 170 & 200 & 180 & 122 & 109 & 122 & 175 & 102 & 91 \\
\hline 14 & $\begin{array}{l}\text { Tugas yang diberikan } \\
\text { sesuai dengan materi } \\
\text { kuliah }\end{array}$ & 191 & 187 & 103 & 108 & 184 & 207 & 187 & 123 & 116 & 128 & 169 & 120 & 101 \\
\hline 15 & $\begin{array}{l}\text { Soal ujian sesuai dengan } \\
\text { materi kuliah }\end{array}$ & 201 & 193 & 118 & 102 & 194 & 216 & 177 & 117 & 113 & 127 & 166 & 114 & 99 \\
\hline & Total & 2.857 & 2.666 & 1.584 & 1.552 & 2.676 & 3.040 & 2.767 & 1.833 & 1.721 & 1.878 & 2.602 & 1.749 & 1.450 \\
\hline & $\begin{array}{l}\text { Pembagi (Total/Jumlah } \\
\text { Kuesioner yang diisi) } \\
\end{array}$ & 47,62 & $\mid 44,43$ & 39,60 & $\beta 8,80$ & 44,60 & 50,67 & 46,12 & 47,00 & 43,03 & 46,95 & 44,10 & 43,73 & 51,79 \\
\hline \multicolumn{2}{|r|}{ Hasil Akhir (Pembagi/15) } & 3,17 & 2,96 & 2,64 & 2,59 & 2,97 & 3,38 & 3,07 & 3,13 & 2,87 & 3,13 & 2,94 & 2,92 & 3,45 \\
\hline
\end{tabular}

Berdasarkan tabel di atas, maka dapat kita peroleh hasil untuk semua dosen. D1 hingga D13 merupakan dosen yang dianalisis, untuk memperoleh total yaitu dengan cara menjumlahkan masing-masing dosen yang mana terdiri 15 point yang tersedia, lalu untuk mendapatkan nilai pembagi yaitu dengan cara hasil total masing-masing sampel dibagi dengan jumlah kuesioner dosen yang diisi, sedangkan untuk memperoleh hasil akhir, penulis menggunakan jumlah total dibagi dengan 15 (jumlah point dari kuesioner). Dari data tersebut D3 dan D4 memiliki nilai terendah, nilai D3 sebanyak 2,67 dan D4 2,59.

Tabel Error! No text of specified style in document..2 Informasi Nilai

\begin{tabular}{|l|c|}
\hline \multicolumn{2}{|c|}{ Catatan : } \\
\hline Sangat Baik Mengajar & $>3,24$ \\
\hline Baik & $>2,74$ \\
\hline Perlu Perbaikan, Kurang Layak Mengajar & $>1,99$ \\
\hline Sangat Perlu Perbaikan, Tidak Layak Mengajar & 0 \\
\hline
\end{tabular}

Berdasarkan informasi dari Tabel 4.2, maka D3 dan D4 perlu perbaikan agar layak menjadi pengajar, karena nilai D3 dan D4 dibawah dari 2,74. Hal ini dilakukan agar kedepannya dosen bisa menguasai materi yang disampaikan serta mampu menciptakan suasana perkuliahan menjadi kondusif. Karena ada kalanya mahasiswa bosan dengan mata kuliah yang selalu membahas tentang teori. Maka sikap dosen harus memberikan semangat dan spirit kepada mahasiswa agar tidak mengantuk. Apalagi disaat jam kuliah siang, rasa bosan mahasiswa pasti menghinggapi. 
Hasil dari kuesioner yang dibagikan, sekitar 98\% mahasiswa yang mengisi kuesioner sangat suka dengan dosen D6. Karena dosen tersebut mengajar dengan materi yang mudah dipahami oleh mahasiswa dan pembawaan dosen yang easy going.

Dari Tabel 4.1, banyak mahasiswa senang dengan dosen yang dapat mencairkan suasana serta bagaimana dosen tersebut menjelaskan materi yang disampaikan. Mahasiswa akan lebih bersemangat jika dosen yang masuk sudah mempersiapkan bahan ajar. Agar perkuliahan berjalan secara maksimal dan tidak mengulur waktu. Dengan begitu, perkuliahan sesuai dengan jadwal yang telah diberikan.

Tabel Error! No text of specified style in document..3 Hasil Perhitungan Analisis Trend

\begin{tabular}{|c|l|c|c|c|c|c|c|}
\hline \multirow{2}{*}{ No } & \multirow{2}{*}{ Keterangan } & \multicolumn{3}{|c|}{ Nilai Kinerja Per Semester } & \multicolumn{3}{c|}{ Trend dalam Presentase Semester } \\
\cline { 3 - 8 } & & VI & IV & II & IV & VI & II \\
\hline 1 & D1 & 964 & 964 & 929 & 100 & 100 & 96 \\
\hline 2 & D2 & 942 & 913 & 811 & 100 & 103 & 89 \\
\hline 3 & D3 & 861 & 723 & 0 & 100 & 119 & 0 \\
\hline 4 & D4 & 822 & 730 & 0 & 100 & 113 & 0 \\
\hline 5 & D5 & 838 & 868 & 970 & 100 & 97 & 112 \\
\hline 6 & D6 & 957 & 1.004 & 1.079 & 100 & 95 & 107 \\
\hline 7 & D7 & 904 & 886 & 977 & 100 & 102 & 110 \\
\hline 8 & D8 & 0 & 852 & 981 & 100 & 0 & 115 \\
\hline 9 & D9 & 814 & 907 & 0 & 100 & 90 & 0 \\
\hline 10 & D10 & 915 & 963 & 0 & 100 & 95 & 0 \\
\hline 11 & D11 & 870 & 799 & 933 & 100 & 109 & 117 \\
\hline 12 & D12 & 0 & 801 & 948 & 100 & 0 & 118 \\
\hline 13 & D13 & 0 & 502 & 948 & 100 & 0 & 189 \\
\hline
\end{tabular}

Hasil pengolahan data dengan metode trend diatas menunjukkan bahwa yang menjadi tahun dasar tersebut adalah semester IV, yang mana seharusnya yang menjadi tahun dasar adalah semester VI. Hal ini dikarenakan di semester VI terdapat beberapa dosen yang belum pernah masuk. Sehingga data yang didapat seperti pada Tabel 4.3.

Dari Tabel 4.3 dapat dijabarkan bahwa angka 0 adalah angka dosen yang tidak pernah masuk di semester tersebut. Kemudian dari hasil trend dalam persentase menujukkan bahwa ada dosen yang mengalami peningkatan dan penurunan di setiap semester. Seperti D6 mengalami penurunan di semester VI sedangkan di semester II D6 mengalami peningkatan. Hal ini disebabkan karena D6 adalah dosen yang baru mengajar di semester VI. Sehingga para mahasiswa perlu beradaptasi lagi dengan dosen baru. Selain itu, yang menjadi faktor naik turunnya trend dosen yang utama adalah tentang mata kuliah yang diajarkan oleh dosen. Mengapa demikian? Karena di semester II dosen lebih mantab dan menguasai materi yang akan diajarkan. Sedangkan untuk semester VI dosen kurang menguasai materi, karena semester VI adalah angkatan pertama di Prodi Akuntansi. Hal itu terkadang membuat dosen perlu mengkaji ulang materi yang akan diajarkan, begitupun dengan mahasiswa semester VI. Mahasiswa semester VI harus belajar ekstra dan kadang-kadang belajar bersama dosen ketika menghadapi kasus yang sulit.

Berdasarkan uraian di atas, maka setiap dosen yang akan mengajar di prodi Akuntansi harus memiliki kemampuan dalam penyampaian materi. Selain itu, dosen harus memberikan ilmu yang ada dengan cara yang disenangi mahasiswa. Agar mahasiswa merasa nyaman saat dosen tersebut mengajar.

\section{KESIMPULAN}

Berdasarkan hasil analisis kinerja dosen saat mengajar dengan menggunakan metode Trend dapat disimpulkan bahwa dari 13 dosen mengajar di program studi akuntansi Politeknik Negeri Tanah Laut terdapat beberapa dosen yang mengalami peningkatan dan penurunan kineja dalam pengajaran di masing-masing semester. Dosen yang memiliki peningkatan dalam kinerja pengajar kepada mahasiswa hal ini dikarenakan dosen tersebut bisa mencairkan suasana dalam mengajar 
dan mampu menjelaskan materi yang disampaikan dengan mudah sehingga mahasiswa tersebut paham apa yang dijelaskan. Selain itu juga, ada dosen yang mengalami penurunan dalam kinerja pengajaran kepada mahasiswa hal ini dikarenakan dosen tersebut kurang mampu mencairkan suasana dalam mengajar sehingga dapat menyebabkan mahasiswa tersebut menjadi mudah mengantuk. Oleh karena itu, dosen-dosen harus bisa menciptakan suasana dalam mengajar baik itu di semester VI, semester IV, maupun semester II agar mahasiswa tersebut dapat menerima apa yang dijelaskan dosen tersebut.

\section{DAFTAR PUSTAKA}

Hamzah, H., Mudjihartono, P., \& Sutoyo, S. (2010). Sistem Pendukung Keputusan Penilaian Kinerja Dosen Dengan MEtode Balanced Scorecard (Studi Kasus : Universitas Respati Yogyakarta). Seminar Nasional Informatika, 82-90.

Hartama, D., \& Hartono. (2016). Analisis Kinerja Dosen STIMIK IBBI Dengan Menggunakan Metode Rough Set. Saminar Nasional Teknologi Informatika dan Multimedia , 49-52.

Pangihutan, F. L., \& Simamora, S. C. (2019). Evaluasi Kinerja Kenuangan dengan Metode Komparatif dan Trend pada PT. Angkasa Pura I (persero) periode 2012-2016. Jurnal Bisnis dan Akuntansi Unsurya, IV, 51-71. doi:10.35968

Permanasari, R., Setyaningrum, R. M., \& Sundari, S. (2014). Model Hubungan Kompetensi Profesionalisme dan Kinerja Dosen. Jurnal Bisnis, Manajemen \& Perbankan, I, 157-174.

Permatasari, I. K. (2019). Analisis Trend penjualan dengan Metode Least Square pada Apotek Swasta Surabaya. Jurnal Mitra Manajemen, 283-298.

Priatna, A. (n.d.). Hubungan Pengembangan profesionalisme dan Kinerja Dosen dalam Meningkatkan Prestasi Belajar Mahasiswa. 1-11.

Razak, Y., Syah, D., \& Hsb, A. A. (2016). Kepemimpinan, Kinerja Dosen dalam Peningkatan Mutu Pendidikan Perguruan Tinggi. Jurnal Penelitian Manajemen Pendidikan, 1, 30-44.

Sestri, E. (2013). Penilaian Kinerja Dosen Dengan Menggunakan Metode AHP Studi Kasus di STIE Ahmad Dahlan Jakarta. Jurnal Liquidity, II, 100-109. doi:10.32546

Fauzi, A. (2016). Analisis Trend Kinerja Pengajaran Dosen Fakultas Ekonomi Universitas Negeri Jakarta Mulai Tahun 2010 s.d 2015. Jurnal Ilmiah Econosains, 14, 1-19.

\section{Biodata Penulis}

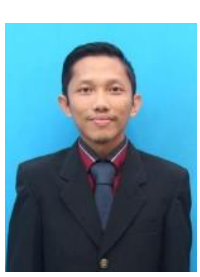

Muhammad Shapiq Gautama, lahir di Pelaihari 28 April 1986. Menempuh pendidikan S-1 Manajemen di Sekolah Tinggi Ilmu Ekonomi Indonesia Banjarmasin lulus pada tahun 2008. Pada tahun yang sama melanjutkan studi S2 Magister Manajemen di Sekolah Tinggi Ilmu Ekonomi Mahardhika Surabaya s dan lulus ahun 2009.Tahun 2010 penulis berprofesi sebagai Karyawan PT.Coca-Cola. Selanjutnyatahun 2011 sebagai Pegawai PT Bank Kalsel dan sekarang tercatat sebagaidosen tetap di rogram Studi Akuntansi Politeknik Negeri Tanah Laut.

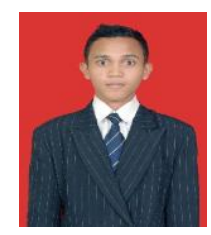

Insan Kamil, lahir di Asam-Asam, 20 Maret 1998. Saat ini sedang menempuh pendidikan D-III Akuntansi di Politeknik Negeri Tanah Laut, selain itu juga aktif pada organisasi Himpunan Mahasiswa Akuntansi dan Kelompok Studi Pasar Modal Politeknik Negeri Tanah Laut .

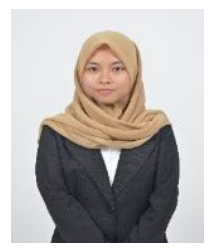

Neng Ayu Rahmawati, lahir di Angsau, 26 Agustus 1998. Saat ini sedang menempuh pendidikan D-III Akuntansi di Politeknik Negeri Tanah Laut, selain itu juga aktif pada organisasi Himpunan Mahasiswa Akuntansi dan Lembaga Pers Mahasiswa Digma Politala. 